\title{
A ATITUDE DE BOA VONTADE E A ABORDAGEM CENTRADA NA PESSOA
}

\author{
THE GOOD WILL ATTITUDE AND THE \\ PERSON CENTERED APPROACH
}

\author{
Dr. Mauro Martins AMATUZZI ${ }^{1}$ \\ Dra. Vera Engler CURY2 \\ Carla Fabiana GRAETZ ${ }^{3}$ \\ Juliana Martensen BELATINI ${ }^{3}$ \\ Marilu Lorete de ANDRADE ${ }^{3}$ \\ Moema Maria SEBER ${ }^{3}$
}

\begin{abstract}
RESUMO
Esta pesquisa teve por objetivo levantar as características da atitude de Boa Vontade, levantar também as características da Abordagem Centrada na Pessoa enquanto uma abordagem mais ampla que sua aplicação no campo da clínica psicológica, e comparar uma coisa com a outra. O método adotado foi qualitativo, de tipo fenomenológico. A comparação mostrou que há semelhanças e diferenças entre as duas, e que a forma como os conceitos são construídos nesse caso e noutro difere. Na idéia de $B V$ o foco é a bondade do ato apontando para o aspecto ético, e na ACP o foco é a relação voltada para o outro confiando nos processos básicos da vida. Da aproximação dos dois conceitos tira-se a conclusão da importância do aspecto ético, entendido como essencial, na formação para ACP e, em geral, na formação do psicólogo.
\end{abstract}

Palavras-chave: boa vontade, abordagem centrada na pessoa, pesquisa fenomenológica.

\begin{abstract}
This research intended to raise the characteristics of the attitude of goodwill, and also the characteristics of the Person Centered Approach, considered as wider than its application to the specific field of clinical psychology, and to compare both of them. The adopted research method was
\end{abstract}

(1) Prof. Dr. do Programa de Pós-Graduação em Psicologia da PUC-Campinas. Docente do Curso de Pós-Graduação em Psicologia. Endereço para correspondência: Av. John Boyd Dunlop s/n - Jd. Ipaussurama - CEP 13059-900.

(2) Profa. Dra. do Programa de Pós-Graduação em Psicologia da PUC-Campinas. Docente do Curso de Pós-Graduação em Psicologia. Endereço para correspondência: Av. John Boyd Dunlop s/n - Jd. Ipaussurama - CEP 13059-900.

(3) Bolsista de Orientação Científica. 


\begin{abstract}
qualitative and phenomenological. The comparison showed that there are some similarities and differences between the two modes and that the way the concepts are built in each considered system differs. Within goodwill the focus is the kindness of the act itself, pointing to ethical aspects, and for PCA the focus is the relationship with other persons, pointing towards trusting the basic processes of life. By approaching these two concepts emerged a conclusion on the importance of ethics, considered here as essential for PCA formation and in general for the psychologist constitution as a professional.
\end{abstract}

Key-words: goodwill, person centered approach, phenomenological research.

A expressão Abordagem Centrada na Pessoa (ACP) veio a ser usada com um sentido mais específico somente depois de outra expressão, Terapia Centrada no Cliente (TCC). Carl Rogers - psicólogo americano responsável pelo desenvolvimento desta abordagem desde a década de cinqüenta - e seus colaboradores perceberam que os princípios utilizados na psicoterapia podiam ser também aplicados em outras situações como educação, relacionamentos interpessoais, grupos, conflitos culturais, etc. A ACP veio então a designar o conjunto de todas essas aplicações, algo mais amplo que a terapia centrada no cliente. Foi mérito do Dr. John Wood (1995) um colaborador direto de Carl Rogers, e que atualmente vive entre nós no Brasil, mostrar que a ACP não era, na verdade, uma aplicação da TCC a outras situações, mas exatamente o contrário. A ACP, enquanto uma abordagem dos problemas humanos, correspondia a princípios gerais que estavam por trás de uma forma de psicoterapia, a TCC, e que podiam também estar por trás do modo de agir em outros campos. A partir daí é que ele pôde buscar uma formulação desses princípios de forma independente da situação da psicoterapia. E nessa formulação já não falava das clássicas três atitudes terapêuticas (empatia, consideração positiva incondicional e congruência) formuladas inicialmente por Rogers num artigo publicado em 1957. Falava sim de coisas mais amplas, capazes, contudo, de englobar essas três atitudes.
O que haveria de específico numa Abordagem Centrada na Pessoa, enquanto algo mais amplo que uma forma de terapia? Será que essas características, na sua generalidade, não acabariam sendo meras descrições do que vem a ser a boa vontade? Ou não será também que a boa vontade não teria muito mais a ver com uma forma de ser que resultaria essencial para a solução de vários problemas humanos? Ou até que os problemas humanos se desenvolveriam, em parte, por falta de boa vontade no relacionamento interpessoal?

Uma sondagem bibliográfica revelou a inexistência de estudos descritivos do que seja a boa vontade (BV) e, obviamente, também a inexistência de estudos relacionando BV e ACP.

Uma pesquisa como essa, além de ser útil na iniciação científica de graduandos de Psicologia (devido à simplicidade de seu delineamento), poderia também propiciar uma reflexão interessante sobre a ACP e seus princípios, e sobre a presença de valores como algo essencial na atuação do psicólogo ou qualquer profissional que lide com o ser humano. A comparação da atitude de boa vontade como modo de ser da abordagem centrada na pessoa traz à baila a importante questão do aspecto ético (explícito na expressão "boa vontade") da atuação profissional. E do aspecto ético não apenas como algo que se acrescenta a uma atitude 
profissional já constituída, mas sim justamente como algo constituinte da própria atitude profissional.

A expressão "boa vontade" aparece em resumos de publicações científicas, mas de uma forma incidental. Não há uma pesquisa que explore o tema em si mesmo.

Um único artigo se aproxima um pouco mais. Bolls, Tan \& Austin (1997) propuseram-se a comparar a atitude de estudantes americanos natos com a de caucasianos a respeito do comportamento comunicativo de professores. Um dos aspectos desse comportamento comunicativo a ser considerado, erajustamente a boa vontade do professor. Concluíram, neste aspecto, que os estudantes americanos percebiam os professores como tendo menor boa vontade do que percebiam os caucasianos. Seria interessante aprofundar um pouco mais essa pesquisa para que pudéssemos determinar como foi medido isso, e qual o conceito subjacente de BV que foi utilizado.

Pudemos notar também que a idéia de $\mathrm{BV}$, mesmo usada incidentalmente, tem dois tipos de uso. Um mais negativo e outro mais positivo.

Francis (1997), escrevendo sobre terapia com crianças, afirma que o progresso terapêutico não depende de sorte ou boa vontade, mas de ferramentas específicas cultivadas pelo terapeuta. Aqui a expressão $B V$ se refere a algo insuficiente.

Westermann (1992) descreve um tipo de cerimônia terapêutica de liberação dos votos matrimoniais no contexto da logoterapia. Afirma que um tal rito de cura conduz ao término um casamento irrevogavelmente perturbado, numa atitude de reverência e, ao mesmo tempo, serve para construir uma ponte de boa vontade para o futuro. Aqui o termo BV tem uma conotação nitidamente positiva.

Também positiva é a conotação do termo quando usada no trabalho de Richman (1991). Falando do suicídio de idosos, defende a idéia de que se poderá salvar vidas e aumentar a felicidade com mais conhecimento a respeito e também com boa vontade tanto por parte da comunidade profissional como da comunidade civil.

No levantamento realizado não encontramos mais do que menções desse tipo e, mesmo assim, em um número pequeno de publicações (não mais do que 15 referências, na maioria livros e não artigos), entre 1991 e 1998. Como já dissemos, o tema não é explorado por si mesmo.

Quanto a artigos científicos mais recentes que se referem à Abordagem Centrada na Pessoa, Patterson (1995) propõe um sistema universal de psicoterapia com princípios derivados da Terapia Centrada no Cliente. De acordo com esse autor, tradicionalmente deuse excessiva importância aos métodos e técnicas psicoterápicas, em detrimento da determinação prévia dos objetivos que, para ele, constituem-se em três níveis: o principal diz respeito ao tipo de pessoa que desejamos que o cliente se torne ao final da psicoterapia; o intermediário refere-se à redução de sintomas para os behavioristas, ou melhoria nas relações interpessoais em terapias familiares e de casal, ou seja, objetivos a médio prazo e há também os objetivos imediatos que concernem a aspectos do próprio processo psicoterapêutico. Para ele, um aspecto essencial do processo terapêutico seria algum tipo de atividade desempenhada ou vivenciada pelo próprio cliente, tal como auto-exploração, ou exploração interpessoal que parecem estar universalmente presentes em psicoterapias bem sucedidas. Segundo o modelo proposto por ele, cabe ao terapeuta promover certas condições para que o cliente se engaje nestas atividades que garantem o sucesso de qualquer processo terapêutico. E elas nada mais são do que as três atitudes definidas por Rogers como compreensão empática, consideração positiva incondicional e congruência ou autenticidade do terapeuta. Resumindo, uma relação terapeuta - cliente, baseada nas "condições necessárias e suficientes para a 
mudança terapêutica de personalidade" propostas por Rogers num artigo clássico escrito em 1957, promoveria a possibilidade de o cliente iniciar sua jornada rumo ao autoconhecimento.

Wood (1996), num estudo de caso sobre cientistas desempregados, conclui que aqueles a quem foi oferecida a oportunidade de reunirse informalmente para conversar sobre sua situação e trocar experiências pessoais foram mais bem sucedidos quanto a arranjar novos empregos ou ocupações do que os que fizeram parte de clínicas de emprego propostas pelo governo americano, de forma a ressaltar a importância dos aspectos interpessoais e do desenvolvimento de uma empatia grupal.

Também Bozarth (1990), examinando as sessões gravadas de psicoterapia e artigos de Rogers para compreender se ele alterou seu funcionamento operacional como psicoterapeuta ao longo dos anos, concluiu que as proposições fundamentais da ACP mantiveram-se consistentes ao longo dos anos, embora com uma ênfase cada vez maior na autenticidade do terapeuta e na expressão de seu self durante os contatos com os clientes.

O'Hara (1998) num capítulo ainda no prelo, sobre Psicoterapia Breve, intitulado "Moments of eternity: what Carl Rogers has to offer brief - therapists", enfatiza a permanência de um paradigma na $A C P$ quanto a uma empatia relacional, presente tanto na terapia a dois (individual) quanto em experiências grupais (grupos intensivos), promovendo uma transformação nos modos de experienciar do cliente, ampliando sua consciência sobre si mesmo, as outras pessoas e o mundo ao seu redor.

\section{A partir desse contexto esta pesquisa pretendeu:}

1) descrever fenomenologicamente a BV a partir de depoimentos vivenciais;

2) caracterizar a ACP enquanto anterior às suas aplicações, a partir da obra de John Wood; e
3) comparar os elementos que compõem a atitude de BV com os que compõem o modo de ser da ACP.

\section{Método}

Trata-se de uma pesquisa qualitativa e que se inspira também em um enfoque fenomenológico.

Para a descrição da estrutura vivencial da boa vontade trabalhou-se a partir de depoimentos colhidos junto a pessoas de qualquer tipo, desde que podendo relatar experiência concreta vivenciada por eles acerca de nosso tema. O número de sujeitos foi estabelecido pelo critério de saturação.

Para a caracterização da ACP o trabalho seguiu inicialmente um caminho documental, partindo-se de escritos de Wood. Posteriormente foi complementada a leitura do autor escolhido com uma entrevista pessoal realizada com ele.

O procedimento junto aos sujeitos que forneceram os depoimentos vivenciais seguiu os seguintes passos:

1) obtenção do consentimento para participar na pesquisa através de um depoimento escrito;

2) solicitação do depoimento através de uma instrução que segue, aproximadamente, o seguinte molde: "Estamos fazendo uma pesquisa sobre a boa vontade. E queremos fazer isso a partir das experiências vividas pelas pessoas. Você pode me contar uma experiência sua a respeito de boa vontade?";

3) não houve nenhuma conversa de esclarecimento com os sujeitos a partir do recebimento do depoimento e foram, posteriormente, excluídos aqueles que não responderam de acordo com o que foi solicitado.

Em relação ao estabelecimento das características da ACP, partiu-se do texto " $\mathrm{Da}$ Abordagem Centrada na Pessoa à Terapia 
Centrada no Cliente: uma retrospectiva de 60 anos" (Wood, 1995). O resumo foi apresentado ao autor.

O plano de análise seguiu, inicialmente, os passos previstos por Giorgi (1985) para pesquisas fenomenológicas em psicologia. Para essa pesquisa ficaram operacionalizados como segue:

1) Leitura de um primeiro depoimento sobre BV para se entrar em contato com seu sentido global.

2) Divisão do texto em unidades de significado.

3) Redação da compreensão psicológica de cada unidade de significado.

4) Síntese do depoimento.

5) Repetição dos 4 pontos acima para outros depoimentos.

6) Busca de uma saturação verificando se os componentes do vivido que puderam ser levantados encontramse em todos os depoimentos considerados.

7) Redação de uma síntese geral sobre estrutura vivida da BV, de acordo com esses depoimentos.

8) Estabelecimento dos pontos descritivos da ACP.

9) Comparação da estrutura da BV com as características da ACP.

10) Redação de resultados encontrados.

11) Discussão desses resultados em face das preocupações da pesquisa.

12) Redação de conclusões.

\section{RESULTADOS}

\section{1) Os depoimentos sobre a BV e sua compreensão psicológica}

Todos os nomes próprios, que constam na transcrição dos depoimentos, são fictícios.

\section{Heloísa, 42 anos}

(1)Uma das coisas que falo e faço de Boa Vontade, é com adolescentes filhos de amigas minhas, ensinando alguma coisa, explicando coisas que os pais estão com dificuldades de fazer. Faço com Boa Vontade. (2)Normalmente recebo retorno, que se "deram" super bem naquilo que "interferi" no sentido de ajudar.

\section{Compreensão:}

1) Heloísa sente-se bem em explicar alguma coisa aos adolescentes, quando seus pais, amigos dela, estão com dificuldades. Ela o faz espontaneamente e acredita ter condições para ensiná-los, sente-se útil já que os pais não estão conseguindo.

2) Heloísa valoriza sua interferência junto aos adolescentes por constatar que efetivamente foi de alguma ajuda.

\section{Síntese:}

Para Heloísa a Boa Vontade refere-se a uma ação para a qual se sente capaz, feita espontaneamente e que a faz sentir-se bem. É importante para ela verificar se sua Boa Vontade foi realmente útil a quem ajudou, cumprindo seu objetivo.

\section{Isabela, 13 anos}

(1) Foi uma vez que eu estava voltando da missa com a minha mãe, uma mulher que estava na minha frente deixou cair do pulso um relógio de ouro.(2) Ela nem percebeu, saiu andando, mas eu peguei o relógio e devolvi a ela.

\section{Compreensão:}

1) Isabela relata sua experiência de Boa Vontade, ao voltar de uma missa, quando presencia a perda de um relógio por uma mulher. 
2) Isabela relaciona a Boa Vontade ao fato de a pessoa não ter percebido a perda do relógio, e ela ter a iniciativa de pegá-lo e devolvê-lo.

\section{Síntese:}

Para Isabela a Boa Vontade está relacionada à sua atitude espontânea em devolver algo de valor material, praticando uma boa ação, demonstrando solidariedade para com a pessoa.

\section{Maria, 62 anos}

(1) Dias atrás fui ao sacolão fazer compras, na saída fui abordada por duas senhoras humildes pedindo informações sobre determinado endereço, (2) ao perceber que as mesmas estavam bem distantes do local ofereci carona e resolvi da forma mais prática.

\section{Compreensão:}

1) Maria descreve um episódio em que duas senhoras humildes solicitam-lhe informações sobre determinado endereço.

2) Percebendo que as senhoras se encontravam distantes do referido endereço, Maria se dispõe a levá-las até o mesmo, considerando que sua atitude foi prática.

\section{Síntese:}

Para Maria a vivência de Boa Vontade implica em uma disponibilidade para auxiliar outras pessoas, em um ato espontâneo, a partir da percepção de uma necessidade, e que se constitui numa ajuda efetiva.

\section{João, 80 anos}

(1) Um exemplo de Boa Vontade são meus netos virem todo domingo de manhã na minha casa trazer almoço para mim (2) e fazer companhia durante a tarde.

\section{Compreensão:}

1) João sente-se querido e bem cuidado quando seus netos vêm trazer o almoço todos os domingos e fazer-lhe companhia, percebendo isto como um ato de Boa Vontade.

2) João sente que seus netos o querem bem, que eles estão presentes em sua vida, pois mesmo tendo compromissos, vêm visitá-lo, ainda que seja só para trazer o almoço.

\section{Síntese:}

João relata um exemplo de Boa Vontade para com ele. Da forma como ele entende, Boa Vontade é agir afetuosamente com pessoas queridas, dedicar-Ihes tempo e atenção e, sendo tratado dessa maneira, sente-se feliz, valorizado e importante.

\section{Mário, 34 anos}

(1) A experiência de Boa Vontade que tive foi em um belo dia de sol, e essa data era o dia 12 de outubro, o Dia da Criança, eu me dirigia pela avenida Flórida sentido centro, estava indo para o clube pegar um bronze (2) quando deparei com um acidente de trânsito debaixo da ponte da rodovia, tive que socorrer duas pessoas para o hospital $X$, onde tive que ficar até às 17:00 h, (3) o meu feriado acabou, mas pude ajudar o meu semelhante e para mim foi muito bom. (4) Como em Rom.13, 8-10: "O Amor cobre multidão de pecados, cuide dos outros como você cuida de você mesmo", e Rom. 12: 21: "Vence o Mal com o Bem".

\section{Compreensão:}

1) Mário viveu esta experiência de Boa Vontade justamente num dia de sol, Dia da Criança, quando se preparava para ir ao clube.

2) Quando teve que socorrer duas pessoas acidentadas, Mário viveu uma mudança inesperada dos seus planos para aquele dia. 
3) Mário, apesar de ter perdido o que havia programado para o seu lazer, em virtude do socorro que prestou ao semelhante, sentiu-se muito bem.

4) Compara sua ação a passagens da Bíblia, em que há a idéia de cuidar do próximo como de nós mesmos e, desse modo, vencer o mal que seria o ato de não ajudar, porque isto acabaria com seu feriado. Vivencia o que fez como sendo coerente com os princípios bíblicos nos quais crê.

\section{Síntese:}

Mário vivencia a Boa Vontade como um ato de amor ao próximo, como um meio de contribuir para a melhora da humanidade, livrando-a dos pecados. Sente-se bem ao ajudar, mesmo quando se sacrifica pelas pessoas, pois assim, segue seus princípios religiosos sobre a bondade, e a necessidade da Boa Vontade para que a humanidade possa livra-se dos pecados.

\section{Laís, 44 anos}

(1) Tenho uma colega de serviço que perdeu a audição dos dois ouvidos de uma maneira repentina e veloz, uma espécie de esclerose auditiva, infelizmente ainda sem cura.

(2) Soube de uma clínica universitária de Fonoaudiologia, localizada na cidade $Y$, e que lá eles poderiam fazer algo a respeito. Liguei para eles, e eles se interessaram pelo caso.

(3) Devido o problema auditivo dessa minha colega me ofereci para acompanhá-la até a clínica universitária, perdendo dois dias de trabalho.

Infelizmente ela não obteve sucesso com a viagem, e durante um bom tempo ajudei-a treinando leitura labial no meu horário de almoço.

\section{Compreensão:}

1) Laís descreve a perda de audição de uma colega que a sensibilizou.

2) Laís toma pessoalmente a iniciativa de ajudar sua colega, conseguindo que uma clínica universitária se interessasse pelo caso.

3) Laís, mobilizada pela necessidade da colega, dispõe-se a acompanhá-la ao serviço médico mesmo perdendo dias de trabalho.

4) Não obtendo resultado com a viagem, prossegue sua ajuda dispondo de seu horário de almoço para treinar leitura labial com sua colega.

\section{Síntese:}

Para Laís, a Boa Vontade é caracterizada por uma disponibilidade de ajuda espontânea a quem está com problemas. Implica em se mobilizar, agir, colaborar no que for possível para solucionar ou minimizar a dificuldade da pessoa.

\section{2) A essência da Boa Vontade}

A partir dos depoimentos colhidos, a BV implica numa disponibilidade, que se manifesta com a percepção de uma necessidade em outra pessoa, para espontaneamente ajudála, visando efetivamente seu benefício. Inclui um sentimento positivo em relação a si mesmo, relacionado com a ação praticada, mas também um sentimento positivo em relação ao outro que recebe a ação.

Destacam-se, portanto, os seguintes elementos:

- Disponibilidade

- Percepção de uma necessidade

- Espontaneidade

- Ajuda

- Visando benefício efetivo

- Sentimento positivo em relação ao outro 
- Sentimento positivo em relação a si mesmo

\section{3) A essência da Abordagem Centrada na Pessoa}

Eis como Wood (1994: III-IV) caracteriza os elementos essenciais da ACP. Diz ele que é um "jeito de ser" (expressão de Rogers) ao se deparar com certas situações. E descreve esse jeito com algumas características.

1) Uma perspectiva de vida, de modo geral, positiva. Ou seja, uma postura prática de quem de fato acredita na vida e em seu valor.

2) Uma crença numa tendência formativa direcional, e aqui Wood cita o próprio Rogers para dizer o que é essa tendência, no caso de pessoas que procuram ajuda psicológica: "Os indivíduos têm dentro de si mesmos amplos recursos para a autocompreensão, para alterarem seu autoconceito, sua atitude básica e seu comportamento autodirigido; esses recursos podem ser mobilizados se thes for proporcionado um clima definido de atitudes psicológicas facilitadoras". Aquela postura prática se fundamenta numa crença operativa em uma tendência ao crescimento, no caso do ser humano ou, de modo mais geral, numa tendência à complexidade e à harmonia.

3) Uma intenção de ser eficaz nos próprios objetivos. Wood menciona que, no caso da terapia centrada no cliente, essa intenção é a de ajudar outro ser humano a fazer mudanças construtivas na personalidade. Fica aberta, no entanto, a possibilidade de outras intenções, em outras situações nas quais só se poderia falar de ajuda em sentido mais metafórico. Por exemplo, a intenção de preservar efetivamente o meio ambiente, na situação de consciência ecológica.

4) Um respeito pelo indivíduo e por sua autonomia e dignidade. E aqui Wood cita novamente Rogers para, a partir do caso da terapia, ilustrar o que isso significa: "uma capacidade de simpatia que não seja exagerada, uma atitude genuinamente receptiva e interessada, uma compreensão profunda que tornaria impossível fazer julgamentos morais ou ficar chocado ou horrorizado"; e também "um respeito, profundamente enraizado, pela integridade da pessoa [...], uma vontade de aceitá-la como é, no seu próprio nível de ajustamento, e lhe dar liberdade para conseguir soluções próprias para seus problemas". Wood lembra aqui que Rogers (citado a partir de Kirschenbaum) considerava que um terapeuta, em função disso, deveria ter "uma sólida compreensão de si mesmo, de seus padrões emocionais predominantes, e suas próprias limitações e atalhos". Ou seja, esse respeito pelo outro, supõe uma boa dose de autoconhecimento, sem o que isso nem poderia acontecer. O que quer dizer também um respeito por si mesmo.

5) Uma flexibilidade de pensamento e ação, não tolhida por teorias ou práticas anteriores, nem mesmo pela experiência, aberta a novas descobertas. E ele comenta isso acrescentando: Uma habilidade de se concentrar intensamente e, com clareza apreender a construção linear da realidade, pedaço-a-pedaço, bem como perceber sua realidade integral, holística, "toda-de-uma-vez". Essa flexibilidade, que se aproxima bastante da atitude fenomenológica voltada para as coisas como se apresentam, implica portanto numa percepção que não se impõe à realidade, mas que a acompanha em seu dinamismo de constituição e, ao mesmo tempo, a apreende toda de uma vez.

6) Uma tolerância quanto às incertezas ou ambigüidades, sendo capaz de viver numa situação caótica até que fatos suficientes se acumulem para ser possível abstrair-se um sentido deles. E ele comenta isso novamente citando Rogers, falando de um interesse "não na verdade já conhecida ou formulada, mas no processo pelo qual a verdade é tenuemente percebida, testada e aproximada". O que 
significa, também, não ter conceitos rígidos ou fixos na apreensão e lida com a realidade.

7) E ele acrescenta que, embora não sejam exclusivos desta abordagem, também têm sua importância aqui o senso de humor, a humildade, e a curiosidade. Afinal ninguém é perfeito nem possuidor definitivo da verdade.

Poderíamos resumir esses pontos como segue:

- Perspectiva positiva de vida

- Crença numa tendência geral ao desenvolvimento

- Intenção de ser eficaz

- Respeito pela autonomia e dignidade do outro

- Flexibilidade de pensamento e ação

- Tolerância com incertezas ou ambigüidades

- Senso de humor, humildade e curiosidade

\section{4) Comparação entre BV e ACP}

A caracterização da BV foi feita mais em termos do ato do que de uma disposição. Para que a comparação com a ACP, enquanto uma abordagem, fosse possível, explicitamos alguns elementos atitudinais pressupostos pela BV. Fizemos isso a partir da constatação de que nos próprios depoimentos existem indicações disso.

- Para Heloísa, a ajuda aos adolescentes não é episódica, mas é algo que ela normalmente faz, mostrando uma disponibilidade para isso.

- Para a garota Isabela, a predisposição fica mais implícita; mas o contexto é o de um ato religioso em que normalmente se prega a bondade.

- Na carona oferecida por Maria, parece que a ação decorreu da percepção de uma necessidade, como se houvesse uma ligação estabelecida, ao menos como predisposição, entre essas duas coisas (se há a necessidade, predisponho-me a ajudar).

- Os netos de João, vêm todo Domingo, o que também sugere que não se trata de um episódio apenas.

- Também para Mário existe uma correspondência entre seu ato de socorrer e coisas que ele acredita ou valores seus.

- Laís parece ser uma pessoa prestativa (e persistente) neste tipo de situação.

A partir dessa pista, associamos aos elementos descritivos do ato de boa vontade algumas características que poderiam explicitar seu significado atitudinal, e que fizessem sentido no contexto dos depoimentos que tínhamos. O resultado dessa "variação imaginativa", típica do método fenomenológico, foi o seguinte:

1. Disponibilidade: abertura ao novo que mobiliza, podendo alterar o rumo das ações; está relacionada a uma flexibilidade de pensamento e ação.

2. Percepção da necessidade: percepção de uma carência objetiva no outro; implica numa atitude de sensibilidade ao outro, relacionada com o respeito pela autonomia e dignidade do outro associado a uma intenção de ser eficaz.

3. Espontaneidade: fazer não contrariado, fazer querendo, a partir de dentro; isso tem a ver com liberdade pessoal e poderíamos dizer que está associado a uma perspectiva positiva de vida humana.

4. Ajuda: é o lado concreto da disponibilidade, voltando-se para o outro; obviamente relaciona-se com a intenção de ser eficaz.

5. Visando benefício efetivo: prolonga o voltar-se para o outro, traduzindo-se em uma prática em seu benefício; 
também está relacionado com a intenção de ser eficaz.

6. Sentimento positivo em relação ao outro: trata-se de um querer bem ao outro (um bem querer, ou um querer bom), de um valorizá-lo de alguma forma; tem a ver com confirmá-lo como ser humano (a partir do interior daquele que age).

7. Sentir-se bem consigo mesmo: tratase da satisfação de ter agido dessa forma em favor do outro; supõe confirmar-se como ser humano.

Nos itens 1, 4 e 5 da BV (disponibilidade, ajuda, e visando benefício efetivo) existe uma correspondência bastante direta com os elementos descritivos da ACP (flexibilidade de pensamento e ação, e intenção de ser eficaz). Nos itens 2 e 3 da BV (percepção da necessidade, e espontaneidade) encontramos uma correspondência também, embora não tão direta, com a ACP (respeito pela autonomia e dignidade do outro associado a uma intenção de ser eficaz, e perspectiva positiva de vida humana).

Os elementos da BV que não têm uma correspondência direta com os da ACP foram os últimos de nossa lista, 6 e 7 (sentimento positivo em relação ao outro, e sentimento positivo em relação a si mesmo), mas também, de certa forma, o 3 (espontaneidade, cuja relação com a perspectiva positiva de vida já supõe uma certa elaboração mais complexa, podendo ser considerada também mais indireta).Por outro lado, os elementos descritivos da ACP que ficaram sem uma correspondência direta com os da BV foram também os últimos, 6 e 7 (tolerância com incertezas e ambigüidades, e senso de humor, humildade e curiosidade), mas também, de certa forma, o 4 (respeito pela autonomia e dignidade do outro), principalmente se considerado isoladamente (pois a boa vontade poderia, às vezes, desrespeitar o outro, quando a pessoa se baseia exclusivamente no que ela acha que é o bem para o outro).

\section{Como compreender esses resultados?}

\section{5) O significado dos resultados}

As semelhanças entre BV e ACP indicam que não são duas formas de ser totalmente díspares.

Mas as diferenças indicam ao menos que as maneiras de se construir a compreensão desses dois modos de ser ou agir não são iguais. Embora a BV seja mais compreendida em termos de atos, ela pode ser ampliada para um conceito atitudinal semelhante a um modo de ser. Viver com um modo de ser de boa vontade. Isso é fato. Apesar disso, no entanto, esse modo de ser se descreve um pouco diferentemente do modo da ACP.

O modo da BV fala mais da "bondade da vontade". Não somente enquanto uma vontade voltada para o que é bom, para um objeto bom, mas também enquanto vontade boa, ou seja, como tendência integrativa da pessoa. Daí porque a sua espontaneidade seja importante. Boa vontade forçada não é ainda uma vontade boa. E daí porque o sentimento positivo em relação ao outro e a satisfação decorrente para o sujeito que vive assim sejam elementos essenciais na descrição desse modo de ser.

Mas a forma de descrever o modo de ser da ACP toma outro caminho. Aqui não é a bondade da vontade o eixo descritivo. Mas sim a forma da relação do sujeito com o mundo, enquanto disposição interna. O que se propõe aqui é estar descentrado de si como indivíduo fechado, e estar centrado no outro como pólo autônomo do diálogo. A ênfase está na abertura da pessoa para o outro. E essa abertura apóia-se na confiança. É por isso que os pontos da ACP que têm menos correspondência direta com o modo de descrever a BV são o respeito pela autonomia e dignidade do outro, considerados não como desinteresse mas justamente o contrário, a tolerância para com incertezas e ambigüidades - porque a segurança da relação não se baseia em certezas objetivas, mas na confiança de que 
as coisas mesmas apontarão seu rumo se eu me relacionar com elas em um clima adequado - e o senso de humor, humildade e curiosidade, pois afinal deve-se abrir mão do sentimento de onipotência, para poder participar de um todo no qual se confia; se houver uma capacidade para facilitar o desenvolvimento de relações criativas, realmente abertas.

Seria a BV o essencial da ACP? A resposta não pode ser simples. Existe provavelmente uma maneira de ser, um modo de se relacionar com o mundo, que é mais criativo e, nas circunstâncias históricas em que nos encontramos atualmente, é a mais biologicamente adaptativa e relacionada com a sobrevivência da humanidade. Mas essa maneira pode ser descrita de formas diferentes, e então com ênfases diferentes. A ênfase da BV é a bondade da vontade, aquela parte de nós mesmos que nos leva a agir de forma consciente e deliberada. A ênfase da ACP é a disposição interna de abertura para o outro, sendo esse outro, na verdade, o mundo de relações como um todo.

Devido a essa diferença de ênfase, alguns aspectos ficam mais bem ressaltados em uma descrição do que na outra. Descrevendo pelo viés da BV ressaltamos a espontaneidade e os sentimentos positivos. Descrevendo pelo viés da ACP ressaltamos o respeito acreditante no outro, a tolerância para com incertezas, a humildade de quem não possui todas as respostas e, no entanto, confia.

\section{Decorrências para a formação de psicoterapeutas em Abordagem Centrada na Pessoa}

A aproximação entre ACP e BV evidencia o caráter daquela como uma abordagem de suprema relevância para o nosso mundo, na medida em que abre a pessoa para o outro numa postura de confiança nos processos mais fundamentais da vida. Por outro lado, chama a atenção para os aspectos éticos dessa relação, na medida em que constrói significados também em torno da bondade da vontade. Nosso querer é fundamentalmente voltado para o que é bom. Isso é uma das manifestações da tendência formativa e atualizante de que falava Rogers. E essa tendência é confiável. À essa luz, os quereres destrutivos, desagregadores, maus, devem ser entendidos como derivados e não básicos.

Esse aspecto ético das relações que a aproximação com a BV permite enfocar na verdade tem papel importante na formação para a ACP. Não se trata de algo acessório como freqüentemente a ética é entendida: regras que limitam as possibilidades de ação. Ao contrário, quando enfocamos a qualidade da vontade envolvida e refletimos sobre isso, estamos, na verdade, tocando na mola propulsora de nosso agir. E é essa mola que também lhe pode dar direção.

$\mathrm{Na}$ formação para ACP é, pois, de importância básica que se contemple as motivações do agir, as qualidades do querer, e que, enfim, se trabalhe a bondade da vontade.

\section{REFERÊNCIAS BIBLIOGRÁFICAS}

BOLLS, P-D; TAN, A; \& AUSTIN, E (1997) An exploratory comparison of Native American and Caucasian student's attitudes toward teacher communicative behavior and toward school. Communication-Education, Vol. 46 (3): 198-202.

BOZARTH, J. D. (1990) The evolution of Carl Rogers as a therapist. Special Issue: fiftieth anniversary of the person-centered approach. Person-Centered-Review, nov, vol. 5(4) 387-393.

CURY, Y. E. (1993) Abordagem Centrada na Pessoa: um estudo sobre as implicações dos trabalhos com grupos intensivos para a terapia centrada no cliente. Tese de Doutorado: Faculdade de Ciências Médicas, UNICAMP. 
FRANCIS, C-A (1997). Tools of play therapy. In: Mark, B S; Incorvaia, J A (Ed.) et al.. The handbook of infant, child, and adolescent psychotherapy, Vol.2: New directions in integrative treatment. Northvale, NJ, USA: Jason Aronson Inc. Pp.117-148.

GIORGI, A (1985) Phenomenology and Psychological Research. Duquesne University Press, Pittsburgh, PA.

O'Hara (1998) Moments of eternity: what Carl Rogers has to offer brief - therapists" (policopiado).

PATTERSON, C.H. (1995) A universal system of psychotherapy. The Person-Centered Journal, Vol. 2:1.

ROGERS, C.R. The necessary and sufficient conditions of therapeutic personality change. Journal of Consulting Psychology, vol. 21(2):95-103,1957.
, (1957) As Condições Necessárias e Suficientes Para a Mudança Terapêutica de Personalidade. In: WOOD, J. K. (1997) Abordagem Centrada na Pessoa. Vitória, Ed. Fundação Ceciliano Abel de Almeida, 1997.

RICHMAN, J (1991) Suicide and the elderly. In: Antoon A Leenaars (Ed.). Life span perspectives of suicide: Time-lines in the suicide process. New York, Plenum Press. Pp.153-167.

WESTERMANN, a (1992) Release from vows of marriage. International Forum for Logotherapy, Vol. 15 (1): 50-52.

WOOD, J. K. et al.(1995) Abordagem Centrada na Pessoa. Vitoria, Ed. Fundação Ceciliano Abel de Almeida,318p.

(1996) The Person - Centered Approach: a case example. Organization-Development - Journal, spr, vol. 14(1) 60-63. 